\title{
Reestruturação e descentralização produtiva, flexibilização e precarização do trabalho na indústria de Catalão (GO)
}

\author{
Restructuring and decentralization, flexibility and precarious \\ work in Catalan (go) industry
}

José de Lima Soares

Doutor em Sociologia pela Universidade de Brasília (UnB). Professor da Universidade Federal de Goiás (UFG)

odijas@uol.com.br

\begin{abstract}
Resumo: O presente trabalho integra um projeto em desenvolvimento sobre reestruturação, descentralização produtiva, precarização e flexibilização do trabalho na indústria de Catalão, centrado na empresa Mitsubishi. Contudo, vale ressaltar que, quaisquer que sejam os "modelos" tecnoorganizacionais, impostos pelo capital, eles funcionam como formas de exploração de mais-valia relativa e absoluta (e como controle social do capital sobre o trabalho). O capital, não esqueçamos, é uma relação social coercitiva. Nesse sentido, é possível considerar o toyotismo como um dos momentos importantes do processo de subsunção real do trabalho ao capital, que atinge as grandes empresas, num cenário de competitividade global sob a regência de políticas neoliberais, pode ser caracterizado, ainda, como uma ofensiva do capital na produção. A crise do capital tende a tornar adequada, para as condições novas de acumulação capitalista mundial, o modelo japonês. Deste modo, as condições sócio-históricas, onde nasceu o toyotismo, um capitalismo de escassez, de mercado restrito, moldaram-no como um conjunto de princípios adequados para o período do capitalismo em crise.
\end{abstract}

Palavras-chave: reestruturação e descentralização produtiva; precarização do trabalho; flexibilização, sindicalismo.

\begin{abstract}
This work is part of a project I have been developing over the restructuring process and the productive decentralization, precarious and flexible working in the Catalan industry. The central axis of our research is the Mitsubishi company. However, it is noteworthy that, whatever the "models" technoorganizational, tax the capital, they function as forms of exploitation of surplus value relative and absolute (and how social control of capital over labor). The capital, lest we forget, is a coercive social relations. Therefore, it is possible to consider toyotism as one of the important moments of real subsumption process of labor to capital, which affects large companies in a global competitive scenario conducted by neoliberal policies, can be characterized also as an offensive of capital in production. The crisis of capital tends to make it suitable to the new conditions of global capital accumulation, the Japanese model. Thus, the socio-historical conditions, the birthplace toyotism a shortage of capitalism, restricted market, shaped it as a set of principles suitable for the period of capitalism in crisis.
\end{abstract}

Keywords: productive restructuring and decentralization; precariousness work; flexibilization, unionism.

Originais recebidos em: 01/10/2015

Aceito para publicação em: 06/05/2016

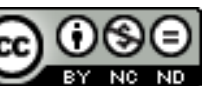

Este trabalho está licenciado sob uma Licença Creative Commons Atribuição-Uso NãoComercial-Vedada a criação de obras derivadas 3.0 Unported License.

Revista Em Debate (UFSC), Florianópolis, volume 14, p. 140-160, 2015. ISSNe 1980-3532 


\section{Introdução}

O objetivo deste artigo é levantar algumas questões pertinentes ao fenômeno da assim chamada descentralização produtiva imposta pelo capital e, com ela, o desdobramento das práticas de flexibilização e precarização do trabalho a partir da implementação da reestruturação produtiva na indústria de Catalão. O ponto de partida é montadora Mitsubishi, a mais importante indústria da cidade de Catalão, localizada no sudeste do Estado de Goiás. Trata-se de uma montadora do setor automobilístico, a MMC Automotores do Brasil (Mitsubishi), de capital nacional.

Com a alteração do paradigma taylorista e fordista para o toyotismo, emergem novos processos de trabalho, onde o cronômetro e a produção em série e de massa são "substituídos" pela flexibilização da produção, pela "especialização flexível", por novos padrões de busca de produtividade, por novas formas de adequação da produção à lógica do mercado. Ensaiam-se modalidades de desconcentração industrial, buscam-se novos padrões de gestão da força de trabalho, dos quais os Círculos de Controle de Qualidade (CCQs), a "gestão participativa", a busca da "qualidade total", são expressões visíveis não só no mundo japonês, mas em vários países de capitalismo avançado e do Terceiro Mundo industrializado. O toyotismo penetra, mescla-se ou mesmo substitui o padrão fordista dominante, em várias partes do capitalismo globalizado (ANTUNES,1997a; 2009). Vivem-se formas transitórias de produção, cujos desdobramentos são também agudos, no que diz respeito aos direitos do trabalho. Estes são desregulamentados, são flexibilizados, de modo a dotar o capital do instrumental necessário para adequar-se a sua nova fase. Direitos e conquistas históricas dos trabalhadores são substituídos e eliminados do mundo da produção. Diminui-se ou mescla-se, dependendo da intensidade, o despotismo taylorista, pela participação dentro da ordem e do universo da empresa, pelo envolvimento manipulatório, próprio da sociabilidade moldada contemporaneamente pelo sistema produtor de mercadorias.

As mudanças tecnológicas e organizacionais tem implicações diretas sobre o processo do que David Harvey (1993) chama de "acumulação flexível” e, consequentemente, no deslocamento das plantas industriais para áreas longínquas, onde não há movimentos sindicais organizados e uma força de trabalho abundantemente precária e barata. Tudo isso funciona muito bem como contratendência do capital. A descentralização produtiva é expressão real desse processo. 
Como bem acentuou Pereira (2012), em sua pesquisa, foi a partir da década de 1990, com a introdução de novos processos da produção enxuta, com destaque para a automação e para a intensificação do trabalho, que o setor automotivo brasileiro conseguiu aumentar a produção e suas vendas com redução de custos, sejam pela eliminação de postos de trabalho, sejam pelos baixos custos que a produção de automóveis adquire na descentralização industrial implementada nesse período no país, em regiões de greenfield (regiões longínquas, "interioranas", onde os salários são baixos, instalações com isenções fiscais, organizações sindicais sem tradição de lutas, desregulamentação do trabalho etc.). $\mathrm{O}$ que atesta a grande produtividade alcançada pela indústria automobilística no Brasil no período. Com a reestruturação produtiva, a Mitsubishi incorporou toda essa lógica, mesclando práticas tayloristas e fordistas com o novo toyotismo.

Outro elemento inerente a essas condições de produção é a alteração no modo como o trabalhador é forjado pela indústria automobilística, onde: são rebaixadas suas condições de vida, por meios econômicos e/ou infra-estruturais da vida urbana; é subordinado politicamente no processo de produção a aumentar o ritmo já extenuante da produção, inclusive pelo caráter semi-mecânico de algumas montadoras (como a MMC); e coagido emocionalmente a vivenciar as relações hierárquicas de mando e disputas internas com outros operários (PEREIRA, 2012, p. 110).

Se tradicionalmente a empresa fordista resultava de um modelo marcado pela rigidez e apto a eliminar custos de transação e garantir o controle do processo de produção, hoje a maior mobilidade dos fatores produtivos e a inovação na organização, as tecnologias ou as comunicações teriam conduzido a um maior interesse empresarial em organizar os processos produtivos sobre o mercado, dado que aquelas inovações facilitam uma redução de custos de transação até situá-los por baixo dos custos que se derivam da organização interna dos processos produtivos empresariais. Esta tese da redução de custos de transação na gestão dos fatores produtivos alcançaria também ao uso da força de trabalho, de forma que um objetivo de "racionalidade econômica" leva ao empresário em um momento determinado a estar mais interessado em procurar este fator produtivo fora da própria empresa, por exemplo, através da contratação ou do trabalho autônomo e precarizado, antes que sua gestão a partir do interior da empresa. Não há dúvida que a descentralização produtiva cumpre esse papel dentro da lógica capitalista. 
De acordo com Alves (2000; 2011), o tempo histórico do capitalismo global pode ser caracterizado pela vigência do regime de acumulação flexível e pela crise estrutural do capital. A terceirização adotada pelas organizações capitalistas ocorre no bojo do complexo de reestruturação produtiva do capital sob o espírito do toyotismo (ALVES, 2000; 2011). Deste modo, a categoria de "terceirização", em comparação, por exemplo, com o putting-out system da indústria capitalista do século XVIII, possui outra significação histórico-ontológica bastante precisa: ela diz respeito a um processo de ofensiva do capital na produção que reorganiza o espaço-tempo da exploração da força de trabalho assalariado nas condições da crise estrutural do capital.

Do ponto de vista coletivo, se no início os trabalhadores lutaram contra a imposição de um novo tipo de trabalho, de um novo tempo a ser dedicado ao trabalho, ao longo da história vê-se que essa nova cultura temporal, aos poucos, acaba fazendo parte de toda a sociedade. O próprio E. P. Thompson $(1987 ; 1998)$, já havia anunciado, em importantes trabalhos, que as mudanças na noção de tempo provocaram mudanças na organização e na orientação social. A noção de tempo adota novo valor (adotado desde as Igrejas até as fábricas), toda a organização social passa a ser controlada pelo tempo e toda a ação social converte-se em "tempo é dinheiro". Seria como se os indivíduos tivessem um "relógio moral interno", um valor internalizado fundamentado na concepção do tempo, por isso situado dentro de uma ética social que se difunde nas fábricas, escolas, na vida das pessoas: formaram-se novos hábitos de trabalho e impôsse uma nova disciplina de tempo.

A primeira geração de trabalhadores nas fábricas aprendeu com seus mestres
a importância do tempo; a segunda geração formou os seus comitês em prol
de menos tempo de trabalho no movimento pela jornada de dez horas; a
terceira geração fez greve pelas horas extras ou pelo pagamento de um
percentual adicional $(1,5 \%)$ pelas horas trabalhadas fora da hora do
expediente. Eles tinham aceito as categorias de seus empregadores e
aprendido a revidar os golpes dentro desses preceitos. Haviam aprendido
muito bem a sua lição, a de que tempo é dinheiro (THOMPSON, 1998, p.
294).

Hoje, a terceirização que ocorre no bojo da nova reestruturação produtiva do capital, na medida em que atinge os coletivos organizados do trabalho, tende a promover uma reordenação socioterritorial dos espaços de produção do capital, implicando não apenas a precarização do trabalho no sentido da corrosão de direitos trabalhistas (inclusive no tocante a negociação coletiva) ou degradação das condições salariais dos homens e mulheres que trabalham, mas também a precarização do trabalho 
no sentido de debilitamento da consciência de classe dos coletivos de trabalho, tendo em vista que desmonta os locis de memória pública e experiências pretéritas de luta de classes.

De acordo com Antunes (1999, p.18-20), mesmo frente à flexibilização do trabalho ocorrida a partir dos anos 70, a indústria fordista com produção taylorista não foi totalmente extinta embora superada pela chamada especialização flexível. Querendo fugir das generalizações, Antunes (1999), busca nas teses de diversos autores encontrar em que medida a especialização flexível substituiu, ou mesmo entrou em simbiose com o modelo fordista. Alguns destes autores alvo do seu estudo argumentam que os novos e flexíveis processos produtivos são inteiramente distintos e substitutos da base fordista, enquanto outros defendem a tese de que não passaram a existir realmente mudanças a tal ponto significativas no interior do processo de produção do capital. Recorrendo a Harvey (1993), Antunes (1999, p. 21), reconhece "a existência de uma combinação de processos produtivos, articulando o fordismo e os processos flexíveis". Certamente a idéia de generalizar as tendências de aumento crucial da flexibilidade e sua mobilidade geográfica, pode trazer distorções, bem como o mesmo pode acontecer ao ignorar-se as práticas da flexibilização em todos os sentidos desta nova fase de acumulação.

Marx e Engels (2010), já haviam demonstrado essa tendência cosmopolita da burguesia em desenvolver, de forma impositiva, as forças produtivas e seu modo de produção social em todo o mundo. Os autores destacam a necessidade da burguesia em revolucionar incessantemente os meios de produção e as relações sociais de produção, não só no ambiente de trabalho, mas em toda a sociedade. A relação do antigo modo de produção com o modo de produção burguês é marcada pela insegurança, pelo abalo entre conservação e subversão contínua:

\footnotetext{
A burguesia não pode existir sem revolucionar incessantemente os instrumentos de produção, por conseguinte, as relações de produção e, com isso, todas as relações sociais. A conservação inalterada do antigo modo de produção era, pelo contrário, a primeira condição de existência de todas as classes industriais anteriores. Essa subversão contínua da produção, esse abalo constante de todo o sistema social, essa agitação permanente e essa falta de segurança distinguem a época burguesa de todas as precedentes. Dissolvem-se todas as reações sociais antigas e cristalizadas, com seu cortejo de concepções e de idéias secularmente veneradas; as relações que as substituem tornam-se antiquadas antes de se consolidarem. Tudo o que era sólido e estável se desmancha no ar, tudo o que era sagrado é profanado e os homens são obrigados finalmente a encarar sem ilusões a sua posição social e as suas relações com os outros homens. [...] Pela exploração do mercado mundial, a burguesia imprime um caráter cosmopolita à produção e ao consumo em todos os países. [...] No lugar do antigo isolamento de regiões e
} 
nações autossuficientes, desenvolvem-se um intercâmbio universal e uma universal interdependência das nações (MARX; ENGELS, 2010, p. 45).

Para compreendermos a situação do trabalho contemporâneo é necessário compreendermos as relações que este trava com as necessidades do capital, conforme apontado acima. E para entendê-las é necessário compreender que no capital enquanto relação social há o que Marx (2011) caracterizou como "função civilizadora", qual seja a ampliação da capacidade de transformação e apropriação da natureza; a intensificação do intercâmbio entre os indivíduos na produção e na sociedade mundial, por meio da interdependência dos processos de produção e circulação (consumo produtivo e improdutivo); dos meios de intercâmbios e comunicação em escala global (especialmente entre os trabalhadores, que assumem, cada vez mais, o caráter de trabalhadores coletivos); a redução do tempo de trabalho ao mínimo necessário à produção de excedentes.

A passagem abaixo demonstra como as transformações na produção implementadas pelo capital promovem transformações nos modos de vida anteriores a ele, e carrega consigo as contradições inerentes a esse modo de produção social da vida:

Portanto, da mesma maneira que a produção baseada no capital cria, por um lado, a indústria universal - isto é, trabalho excedente, trabalho criador de valor -, cria também, por outro lado, um sistema da exploração universal das qualidades naturais e humanas, um sistema da utilidade universal, do qual a própria ciência aparece como portadora tão perfeita quanto todas as qualidades físicas e espirituais, ao passo que nada aparece elevado-em-si mesmo, legítimo-em-si-mesmo fora desse círculo de produção e troca sociais. Dessa forma, é só o capital que cria a sociedade burguesa e a apropriação universal da natureza, bem como da própria conexão social pelos membros da sociedade. Daí a grande influência civilizadora do capital; sua produção de um nível de sociedade em comparação com o qual todos os anteriores aparecem somente como desenvolvimentos locais da humanidade e como idolatria da natureza. Só então a natureza torna-se puro objeto para o homem, pura coisa da utilidade; deixa de ser reconhecida como poder em si; e o próprio conhecimento teórico das suas leis autônomas aparece unicamente como ardil para submetê-la às necessidades humanas, seja como objeto do consumo, seja como meio da produção. O capital, de acordo com essa sua tendência, move-se para além tanto das fronteiras e dos preconceitos nacionais quanto da divinização da natureza, bem como da satisfação tradicional das necessidades correntes, complacentemente circunscrita a certos limites, e da reprodução do modo de vida anterior. O capital é destrutivo disso tudo e revoluciona constantemente, derruba todas as barreiras que impedem o desenvolvimento das forças produtivas, a ampliação das necessidades, a diversidade da produção e a exploração e a troca das forças naturais e espirituais (MARX, 2011, p. 333).

De fato enquanto nos países centrais ainda se concentrava a produção industrial, as novas tecnologias e a força de trabalho antes refugada, se tornaram estratégias fundamentais. Quando o capital adquiriu mobilidade suficiente, passou a buscar novas 
regiões para produzir em áreas de baixos salários, e também se valorizar financeiramente em paraísos fiscais, que se proliferavam nos anos de 1970. Esse processo de flexibilização da produção e acumulação permite ao capitalista exercer uma maior pressão sobre a vida dos trabalhadores, estes que já vêm suas lutas enfraquecidas com o esvaziamento sindical e redução cada vez maior de direitos vislumbrados nesta "era neoliberal".

Embora o padrão toyotista represente um aparente avanço nas relações entre patrões e empregados, na medida em que estes se vêm com maior participação e autonomia dentro do espaço organizacional, há que se chamar atenção para o fato de que as mudanças propostas por esse modelo de acumulação em nada favoreceram o trabalhador.

Nesse sentido, a descentralização produtiva está tendo efeitos evidentes sobre as relações trabalhistas:

- Generalizam-se os mecanismos de flexibilidade interna;

- Desenvolvem-se os mecanismos de flexibilidade externa;

- Diversificam-se os estatutos jurídicos nas relações trabalhistas, com uma clara diferenciação entre os trabalhadores da empresa principal e os das empresas auxiliares, e entre os trabalhadores autônomos;

- Reduz-se o campo de relação contratual do trabalho e se expandem as formas civis e mercantis de prestação de serviços.

A descentralização produtiva não é um fenômeno novo. É uma prática imposta pelo capital em várias regiões do planeta, mas que nas duas últimas décadas vem se intensificando nos países periféricos. Alguns autores como David Harvey (1993) já havia levantado essa questão do deslocamento de empresas para áreas longínquas e remotas, distantes das grandes metrópoles, e sem tradição sindical, como no caso do Vale do Silício. O que está por trás dessa política é a desregulamentação do trabalho. No Brasil, como indica Ricardo Antunes:

\footnotetext{
Várias fábricas de calçados, por exemplo, transferiram-se da região de Franca, no interior de São Paulo, ou da região do Vale dos Sinos, no Estado Grande do Sul, para estados do Nordeste, como no Ceará e Bahia e hoje começam a pensar em transferir parcela de sua produção para o solo chinês. Indústrias consideradas modernas, do ramo metalomecânico e eletrônico, transferiram-se da Região da Grande São Paulo para áreas do interior paulista (São Carlos e Campinas) ou deslocaram-se para outras áreas do país, como interior do Rio de Janeiro (Resende), ou ainda para o interior de Minas Gerais (Juiz de Fora), ou outros estados como Paraná, Bahia, rio Grande do Sul. E hoje examinam possibilidades de transferência de parte da produção para a
} 
China. Novas plantas foram instaladas, como a Toyota e Honda, ambas na região de Campinas, dentre tantos outros exemplos” (ANTUNES, 2007, p. $15)$.

A necessidade de elevação da produtividade dos capitais em nosso país vem ocorrendo, então, vem fundamentalmente através de reorganização sócio-técnica da produção, da redução do número de trabalhadores, da intensificação da jornada de trabalho dos empregados, do surgimento dos Círculos de Controle de Qualidade (CCQ’s) e dos sistemas de Just-in-time, kanban, kaizen, células de produção, entre outros elementos.

Foi quando o fordismo aqui vigente sofreu os primeiros influxos do toyotismo. A partir anos 1990 essa processualidade deslanchou através da implantação dos receituários oriundos da acumulação flexível e do ideário japonês, seguidos da intensificação da lean production, das formas de subcontratação e de terceirização da força de trabalho, da transferência de plantas e unidades produtivas, onde empresas tradicionais, como a indústria a indústria têxtil, sob imposição da concorrência internacional, passaram a buscar, além de isenções fiscais, níveis mais rebaixados de remuneração da força de trabalho, combinados com uma força de trabalho sobrante, sem experiência sindical e política, pouco ou nada taylorizada e fordizada e carente de qualquer trabalho.

Dando ênfase a terceirização da produção no modelo toyotizado (não esquecendo de todas as características do modelo apresentado acima), isso porque há uma complexa relação deles com a mudança da exploração, assim como na intensificação do trabalho da classe trabalhadora, cria-se uma produção flexível, em distintos espaços, que poderá estar distantes do núcleo de produção. Como por exemplo, a montadora de automóveis Mitsubishi em Catalão (GO) que produz veículos com peças de diferentes lugares, como, por exemplo, peças que vem de várias regiões do Japão, da Europa entre outras do mundo. Com isso, a fábrica toyotizada tem um núcleo de produção, cercado de empresas terceiras que produzem peças, acessórios entre outros e, também, possui firmas terceirizadas a milhares de quilômetros, produzindo peças que compõe a mercadoria final que é montada no núcleo de produção. É desse modo que a intensificação do trabalho ocorre. Com a fragmentação da produção em diferentes espaços e diferentes territórios, a dificuldade dos trabalhadores de se organizarem é imensa. Em consequiência disso, o capital explora com mais intensidade a força de 
trabalho, a partir de diferentes estratégias. Antunes (1999, p. 56), explica como é o modo de trabalho de uma fábrica nos padrões do toyotismo:

O processo de produção de tipo toyotista, por meio dos team work, supõe portanto uma intensificação da exploração do trabalho, quer pelo fato de os operários trabalharem simultaneamente com várias máquinas diversificadas, quer pelo ritmo e a velocidade da cadeia produtiva dada pelo sistema de luzes. Ou seja, presencia-se uma intensificação do ritmo produtivo dentro do mesmo tempo de trabalho ou até mesmo quanto este se reduz. Na fábrica Toyota, quando a luz está verde, o funcionamento é normal; com a indicação da cor laranja, atinge-se uma intensidade máxima, e quando a luz vermelha aparece, é porque houve problemas, devendo-se diminuir o ritmo produtivo. A apropriação das atividades intelectuais do trabalho, que advém da introdução de maquinaria automatizada e informatizada, aliada à intensificação do ritmo do processo de trabalho, configuram um quadro extremamente positivo para o capital, na retomada do ciclo de acumulação e na recuperação da sua rentabilidade.

Inaugurada em 1998, a montadora pertence ao grupo Souza Ramos e produz veículos da marca Mitsubishi. Atualmente a fábrica monta em média 200 carros por dia e quatro modelos diferentes, sendo eles: Pajero Dakar, L200, ASX e Lancer. A empresa ainda nacionaliza outros modelos provenientes do Japão, dentre eles: Outlander e Pajero Full. A empresa, inicialmente, empregava cerca de 150 trabalhadores; hoje emprega 2.800 trabalhadores diretos e 1.500 indiretos (terceirizados). No início, a fábrica possuía capacidade de montagem de 10.000 veículos por ano; atualmente a produção anual é de 48.000 veículos.

$\mathrm{Na}$ verdade, o surgimento da Mitsubishi tem uma história. De acordo com Erik Sousa (2010), em 1991, a Brabus obteve licença para importar e distribuir veículos e peças da marca Mitsubishi Motors Corporation, tornando-se representante exclusiva da marca japonesa no Brasil. A empresa tem como objetivo social a comercialização, importação e exportação de veículos automotores novos e usados, de peças, partes, acessórios e equipamentos em geral para veículos automotores; prestação de serviços de assistência técnica em geral, destinados à conservação, manutenção, reparos e blindagem de veículos automotores, além de promoção de eventos esportivos, treinamento profissional, entre outras (SOUSA, 2010, p. 33).

Recentemente, a Mitsubishi, ao implementar a reestruturação produtiva, acabou aprofundando a flexibilização e a precarização do trabalho, providenciando a separação dos trabalhadores terceirizados em quatro novas empresas: a PRC (motores e chassis de propulsão); a BW \& P (solda e pintura); a Mitsubishi Seguros (parte de vendas e seguros); e a Mitsubishi (montagem de componentes). Com a inauguração do novo 
prédio da pintura (projeto financiado pelo BNDES), a empresa pretende ampliar a produção passando de 200 para 400 modelos por dia.

Logo que implantou todo esse processo de reestruturação, em menos de cinco meses, a montadora começou uma escalada de demissões em massa. Até junho de 2015, a empresa empregava, segundo o sindicato dos trabalhadores, cerca de 3 mil trabalhadores, mas em meio à crise, em menos de 2 meses, cerca de 700 trabalhadores foram demitidos. Enquanto isso, a previsão é que o cenário tende a se agravar. A partir do acordo firmado com o sindicato, a empresa pode dispensar um trabalhador por dia durante os próximos seis meses, totalizando mais de 180 demissões. O impacto das demissões sobre a economia da cidade de quase 100 mil habitantes, já são visíveis. De acordo com o sindicato dos trabalhadores (SIMCAT), a montadora é o carro-chefe de arrecadação do município e de geração de emprego, seja direta ou indiretamente. Com as demissões, o sindicato do comércio (SINDCOM) estima que a perda de arrecadação do município deva chegar a 1,5 milhões de reais.

Os salários dos trabalhadores são relativamente baixos, se comparados com os de outros Estados. Segundo o sindicato dos metalúrgicos, a média salarial é de R\$ $1.600,00$, podendo chegar até R $\$ 5$ mil em alguns casos. Para a maioria oriunda da região a situação salarial dos operários ainda repercute nas condições de moradia:

\footnotetext{
Os salários pagos pela Mitsubishi, além de ser muito inferior aos dos colegas operários de outros Estados, ficam muito aquém do ritmo de valorização do solo urbano. É forçoso concluir que os problemas de moradia para o operariado, para outros grupos de baixa renda, desempregados e recém chegados à cidade tornam-se mais freqüentes e que eles sentirão de maneira mais intensa a especulação imobiliária. Mas não apenas eles, todos os cidadãos, bem ou mal empregados, puderam perceber tal valorização. Aliás, este é o outro lado da industrialização, pois muito em breve os serviços públicos e a infra-estrutura urbana poderão estar muito aquém do ritmo de crescimento populacional motivado pela busca de emprego em Catalão (SILVA, 2002, p. 124).
}

Nos discursos, a Mitsubishi Motors aparece como solucionadora de todos os problemas do Município, não revelando as verdadeiras intenções da sua territorialização no interior do país. A apropriação da força de trabalho a partir da interiorização da atividade industrial promovida pelas montadoras nas últimas décadas no Brasil, tem se tornado uma nova forma de assegurar a reprodução simples e ampliada do capital. Desejam, essencialmente, uma força de trabalho barata, pouca ou nenhuma organização sindical, mas também aspectos geográficos favoráveis como ponto estratégico de logística (posição geográfica) e incentivos creditícios e físcais. 
A territorialização dessas indústrias provocou importantes transformações na Microrregião de Catalão, contribuindo sobremaneira para a mudança no perfil econômico, social e cultural de Catalão e certamente lançaram as bases para a consolidação do início do processo de industrialização da economia. O primeiro é a intensificação da mobilidade do trabalho e na alteração relação cidade-campo, sobretudo, a partir da década de 1970. O segundo, as sucessivas transformações no espaço urbano, decorrentes da territorialização do capital industrial e financeiro (SANTANA, 2011).

Santana, em sua pesquisa, conseguiu apreender os aspectos centrais das mudanças ocorridas na indústria de Catalão, com destaque para a MMC Automotores do Brasil S/A. Ao analisar as principais mudanças nos processos produtivos, o pesquisador entende que as transformações espaciais promovidas pela reestruturação produtiva do capital alteraram profundamente a relação entre o capital e o trabalho. Como reflexo desta nova dinâmica, a mobilidade geográfica do capital acabou gerando uma descentralização produtiva para outras regiões do país, onde sequer havia organizações dos trabalhadores, capazes de se contrapor as práticas de precarização e flexibilização do trabalho. O caso da Mitsubishi é emblemático: uma montadora nacional, instalada entre 1997/98, estabeleceu um novo padrão de reprodução do capital no Sudeste Goiano. Atualmente a Mitsubishi somando-se às terceirizadas contratam em torno de 3.000 trabalhadores, em sua grande maioria representados pelo Sindicato dos Trabalhadores Metalúrgicos de Catalão (SIMECAT), fundado em 2004 e filiado à Central Força Sindical.

Santana constatou ainda que a precarização do trabalho, os métodos de organização da produção, os diversos mecanismos de controle social, entre os quais destacam-se a Participação nos Lucros e Resultados, o trabalho em equipe permeado pelo discurso da cooperação, a terceirização e a contratação de trabalhadores de várias cidades da Microrregião de Catalão, mostram que a expansão geográfica do capital atinge profundamente a classe trabalhadora, sobretudo a sua capacidade de organização e mobilização.

Marques e Avelar (2010) fizeram uma análise interessante sobre os reflexos às pressões na intensificação do trabalho, e como esta se reflete em doenças ocupacionais nos operários da MMC. Os autores alegam que a gerência de produção pressiona os operários para não haver re-trabalho, entendido como um custo desperdiçado. E quando 
há a necessidade do re-trabalho o mesmo é feito em horário extra da equipe responsável pelas falhas.

Mesmo no horário regular de trabalho há uma série de movimentos e posturas que afetam a saúde do trabalhador, fundamentalmente nos ombros, braços e coluna, uma vez que boa parte do trabalho é manual, fundamentalmente nas transições onde se usam os guindaste e elevadores e no encaixe dos componentes mais pesados.

Disso decorrem os processos na justiça do trabalho abertos pelos operários contra a empresa:

\begin{abstract}
Seguindo essa linha de raciocínio, é notória a existência de vários processos contra a montadora Mitsubishi que não se responsabiliza pelos acidentes, de vez que, segundo consta no site da vara do trabalho encontra-se tramitando onze processos sem mencionar os que já foram julgados ao longo da existência da indústria na cidade de Catalão (GO). A empresa contrata médicos e advogados para contradizer os trabalhadores. Além disso, a falta de reconhecimento da questão, como acidente de trabalho, retira dos trabalhadores vários direitos e, ainda, danos à saúde do trabalhador difíceis de ser curados, segundo médicos especializados. Produzem um trabalhador ainda muito jovem, mas permanentemente descartável (MARQUES; AVELAR, 2010, p. 74).
\end{abstract}

A explicação dessa postura por parte da empresa está no fato de que uma vez que os operários entram com recursos, junto ao INSS, alegando acidente ou doença adquirida no trabalho recebem boa parte dos benefícios para que cuidem dos problemas desenvolvidos dentro da empresa. Na perspectiva da empresa isso significa dois custos, ou seja, no respeito ao direito de estabilidade de 1 ano, estabelecido por lei, e onerando as despesas com elevação da contribuição fiscal ao órgão, em função do aumento do índice de acidente de trabalho. É nesse sentido que os operários se tornam descartáveis para a empresa e, muitas vezes, para a sociedade quando encontram dificuldades de se reempregar, em virtude das doenças e limitações de movimentos físicos adquiridas durante a produção da MMC.

Autores como Armando Boito Jr. (2003; 2005), Giovanni Alves (2000; 2009; 2011), Ricardo Antunes (2005; 2006a; 2006b; 2011), Ariovaldo Santos (2004; 2006), Graça Druck (2006; 2007; 2011), Andréia Galvão (2007), Sadi Dal Rosso (2008), entre outros, tem insistido que o processo de reestruturação produtiva, nos últimos anos, tem levado a uma profunda intensidade do trabalho, seguido da flexibilização e da precarização. Fazendo um retrospecto da bibliografia dos autores que tratam do tema, é possível destacar que desde o governo FHC, passando pelo governo de Lula da Silva tem havido uma intensificação do processo de flexibilização e precarização do trabalho. 
A bibliografia pesquisada indica sobremaneira que o trabalho precário e $\mathrm{o}$ processo de flexibilização se inserem na lógica da exploração da força de trabalho nos marcos da ordem do capital. Do setor industrial ao setor de serviços, do trabalho formal ao trabalho informal, incontáveis sujeitos vivem longe das possíveis vantagens que vêm do núcleo privilegiado do capitalismo. Embora em nossa sociedade atual seja quase uma redundância falar em 'trabalho precário', alguns poucos trabalhadores conseguem fazer de sua atividade laboral uma fonte de prazer, estabilidade e dinheiro. Mas a maioria encontra-se obrigada, com mais ou menos intensidade, a conviver com as várias facetas da precariedade no trabalho (PADILHA, 2010).

Para Galeazzi (2006) a precarização do trabalho é entendida como situações laborais que se tornaram expressivas com a ocorrência da chamada 'reestruturação produtiva' sob a égide neoliberal. De acordo com a autora, "a definição de trabalho precário contempla pelo menos duas dimensões: a ausência ou redução de direitos e garantias do trabalho e a qualidade no exercício da atividade" (GALEAZZI, 2006, p. 203). Assim, a precarização do trabalho é considerada uma das formas de assalariamento atípico, o trabalho assalariado não regulamentado, a subcontratação, o trabalho por tempo determinado, o trabalho em tempo parcial e a contratação de cooperativas de trabalho como uma forma especial de terceirização.

Diante desse quadro, podemos definir o trabalho precário como um conjunto de fatores - os quais podem ou não estar combinados - que caracterizam a atividade laboral de inúmeros trabalhadores. Os principais fatores são: a) desregulamentação e perdas dos direitos trabalhistas e sociais (flexibilização das leis e direitos trabalhistas); b) legalização de trabalhos temporários, em tempo parcial, e da informalização do trabalho; c) terceirização e quarteirização ('terceirização em cascata'); d) intensificação do trabalho; e) aumento da jornada de trabalho (duração do trabalho) com acúmulo de funções (polivalência); f) maior exposição a fatores de riscos para a saúde; g) rebaixamento dos níveis salariais; h) aumento da instabilidade no emprego; i) fragilização dos sindicatos e das ações coletivas de resistência; j) feminização da força de trabalho; k) rotatividade estratégica (para rebaixamento de salários) (PADILHA, 2010).

O conceito de precarização do trabalho diz respeito às distintas formas de rebaixamento salarial, degradação das condições de trabalho, retirada de direitos trabalhistas historicamente conquistados e fragmentação da classe operária, atingindo 
homens e mulheres. Sinteticamente, pode-se afirmar que nessas décadas o capitalismo avançou sobre as conquistas dos trabalhadores e dos povos oprimidos do mundo, desta vez este conjunto de ataques foi levado adiante, destruindo os coletivos de trabalhadores, através de uma revolução molecular no seio do processo produtivo, ou seja, daquilo que Antonio Gramsci (2002) de "revolução passiva". Assim, houve um enorme ataque às condições de trabalho e de vida de toda a classe trabalhadora, que consistia em criar subcategorias, possibilitando que em uma mesma empresa ou fábrica existam trabalhadores que realizam o mesmo serviço com salários e direitos distintos, criando assim um abismo entre as classes trabalhadoras. Esta divisão se dá ao mesmo tempo em que os efetivos também perdem direitos e condições em relação à etapa anterior ao neoliberalismo. É o que autores como Boito Jr. e Antunes denominam de neocorporativismo societal. Ou seja, alguns sindicatos conseguem lutar em prol dos trabalhadores e categorias mais organizadas, em detrimento dos setores precarizados, terceirizados, subcontratados.

Para Vasopollo (2005), o trabalho precário equivale ao 'trabalho atípico'. É o que o autor caracteriza como "nova organização capitalista do trabalho marcada pela precariedade, pela flexibilização e desregulamentação, de maneira sem precedentes para os assalariados. É o mal-estar no trabalho (...) com a angústia vinculada à consciência de um avanço tecnológico que não resolve as necessidades sociais. É um processo que precariza a totalidade do viver social" (VASAPOLLO, 2005).

Chama a atenção a perspectiva crítica do autor ao definir a flexibilização do trabalho como um processo onde há liberdade da empresa para despedir parte de seus empregados, sem penalidades, quando a produção e as vendas diminuem; liberdade da empresa para produzir ou aumentar o horário de trabalho, repetidamente e sem aviso prévio, quando a produção necessite; faculdade da empresa de pagar salários reais mais baixos do que a paridade de trabalho, seja para solucionar negociações salariais, seja par poder participar de uma concorrência internacional; possibilidade de a empresa subdividir a jornada de trabalho em dia e semana de sua convivência, mudando os horários e as características (trabalho por turno, por escala, em tempo parcial, horário flexível etc.); liberdade para destinar parte de sua atividade a empresas externas; possibilidade de contratar trabalhadores em regime de trabalho temporário, de fazer contratos por tempo parcial, de um técnico assumir um trabalho por tempo determinado, subcontratado, entre outras figuras emergentes do trabalho atípico, diminuindo o 
pessoal efetivo a índices inferiores a $20 \%$ do total da empresa. Ou seja, a flexibilização do direito do trabalho consubstancia-se no conjunto de medidas destinas a afrouxar, adaptar ou eliminar direitos trabalhistas de acordo com a realidade econômica e produtiva.

É o que Ricardo Antunes $(1999 ; 2007)$ tem chamado de "dimensões da precarização estrutural do trabalho". A classe trabalhadora desprovida de direitos e sem carteira assinada, desemprego ampliado, seguido da precarização exacerbada e do rebaixamento salarial acentuado.

Para Bourdieu (p. 123 e 124) a precarização está presente em toda parte e atinge grande parte da população, operários, empregados no comércio e na indústria, professores, jornalistas e estudantes. É o que ele chama de novo modo de dominação sobre o trabalho e os trabalhadores:

\begin{abstract}
A precariedade atua diretamente sobre aqueles que ela afeta e indiretamente sobre todos os outros pelo temor que ela suscita e que é metodicamente explorado pelas estratégias de precarização, com a introdução da famosa "flexibilidade". Começa-se assim a suspeitar que a precariedade seja o produto de uma vontade política, e não de uma fatalidade econômica, identificada com a famosa "mundialização". A precariedade se inscreve num modo de dominação de tipo novo, fundado na instituição de uma situação generalizada e permanente de insegurança, visando obrigar os trabalhadores à submissão, à aceitação da exploração. Apesar de seus efeitos se assemelharem muito pouco ao capitalismo selvagem das origens, esse modo de dominação é absolutamente sem precedentes, motivando alguém a propor aqui o conceito ao mesmo tempo muito pertinente e muito expressivo de "flexploração" (BOURDIEU, 1998, p. 123-124).
\end{abstract}

No tocante à questão da flexibilização e a precarização do trabalho, autores como Boito Jr., Paula Marcelino e Andréia Galvão (2009), insistem que durante os governos Lula da Silva houve uma reconfiguração do movimento sindical, ou seja, alterou-se o cenário sindical brasileiro significativamente. A proliferação das Centrais Sindicais não significou um avanço na retomadas das lutas contra a ofensiva do capital. De forma que, mesmo com a participação massiva dos dirigentes sindicais na máquina administrativa do governo, não houve nenhuma resistência organizada importante, por parte das Centrais, contra a retirada de direitos dos funcionários públicos. Os novos servidores perderam o direito à aposentadoria dos servidores com vencimento integral e seus benefícios deixaram de ser reajustados na mesma proporção que os salários dos servidores ativos. Os critérios para a aposentadoria dos servidores já em exercícios tornaram-se mais rígidos, de modo a dificultar-se a obtenção da aposentadoria integral. A perda sofrida no valor da aposentadoria seria supostamente compensada pela 
expansão dos fundos de pensão, destinados a assegurar uma aposentadoria complementar. Também implementou-se algumas medidas flexibilizantes, a exemplo da contratação de prestadores de serviços na condição de empresas constituídas por uma única pessoa (a chamada "pessoa jurídica") e da lei do Super Simples, que possibilita a redução de alguns direitos trabalhistas para micro e pequenas empresas (BOITO Jr., MARCELINO e GALVÃO, 2009).

As grandes mudanças no mundo do trabalho, a reestruturação produtiva, impostas pelo capital - ao longo dos anos 1990/2000 - encontram sua expressão maior na dialética lei do desenvolvimento desigual, combinado e contraditório das sociedades contemporâneas e mediadas por um intenso processo de globalização capitalista (Ianni, 1992; Marques, 1996). Nesse contexto, de acordo com Ramalho (1997), tanto nos países centrais como nos periféricos, a situação das classes trabalhadoras e de suas entidades de classe trazem, respectivamente, as marcas de origem da exclusão social, do desemprego estrutural, da superexploração do trabalho e da precarização, somando-se ainda, a crise do sindicalismo.

De acordo com alguns pesquisadores como Guimarães e Ribeiro (2006), Silva (2010) e Santana (2011), o que tem tornado mais atrativo a territorialização dessas empresas na região de Catalão (nesse processo de descentralização produtiva), tem sido o barateamento da força de trabalho (os baixos salários) e a ausência de uma tradição sindical de luta, além de uma classe trabalhadora abundantemente jovem (entre 18 e 35 anos), formada e treinada no SENAI, que está exclusivamente voltada para atender às necessidades das grandes empresas locais. Além disso, sua concepção de formação e qualificação é vendida ideologicamente como se fosse a forma mais fácil de se conseguir um bom emprego na cidade. Assim, a função ideológica do SENAI se expressa na contradição de se individualizar um problema de caráter coletivo e social, que é o desemprego. Ora, se é verdade que a escola reproduz a lógica do sistema capitalista de exploração, a formação do SENAI não busca uma educação voltada para a potencialização das capacidades humanas, mas, sim, está em sintonia com as demandas do mundo empresarial burguês (MENDES apud SANTANA, 2011, p. 92).

De acordo com Mendes (2007) o SENAI desempenha, a serviço do capital, a função de educação para o trabalho, assistência técnica e tecnológica para a indústria. Incomodados com a ideia simplista de que a qualificação profissional detém a função de combater o desemprego, prestando um serviço ao trabalhador e incorporando assim uma 
espécie de passaporte para a empregabilidade. Verificamos que o discurso da qualificação profissional está revestido de um caráter cidadão, porém essencialmente ideológico no sentido marxiano do termo, ou seja, de falseamento da realidade. Do ponto de vista da práxis social, nos deparamos com um ambiente pedagogicamente estruturado para o adestramento e o treinamento da mão-de-obra para indústria. Percebemos assim, que a qualificação profissional se eleva enquanto poderoso mecanismo de controle social do capital sobre o trabalho. Sua finalidade é disciplinarizar o trabalho e os trabalhadores, ou seja, capacitá-los técnica e ideologicamente para o mercado. Não é difícil compreender o sentido dessa qualificação, basta analisar que, do ponto de vista do conhecimento técnico, há o aumento da produtividade do trabalho nas indústrias e do ponto de vista ideológico, há a difusão constante da cultura empresarial, o que possibilita a (re)produção dos valores de vida capitalistas entre os trabalhadores. Monta-se então uma estrutura educacional, uma pedagogia da fábrica, na qual o SENAI está inserido. É por meio dessa dimensão intelectual e alienada do trabalho, que o capital moderno se apropria da inteligência do trabalhador, criando um caminho original de racionalização do trabalho contemporâneo, ou seja, a captura de sua subjetividade. Tanto que o SENAI se modifica em função do movimento de reestruturação produtiva do capital, adequando-se as novas exigências do mercado por novas qualificações do trabalho (MENDES, 2007).

\section{Considerações finais}

Ao longo deste trabalho procuramos compreender, com base no método dialético, como o sistema capitalista, com base em um desenvolvimento desigual, combinado e contraditório, conseguiu engendrar um processo de expansão geográfica que repercute no estado de Goiás, através de um desenvolvimento industrial que traz no seu bojo a marca de origem da descentralização e da reestruturação produtiva, responsáveis pela precarização, flexibilização do trabalho e o desemprego em massa. $\mathrm{O}$ que expressa, na concepção de István Mészáros, uma lógica destrutiva do capital!

Sugerimos a hipótese de que as organizações dos trabalhadores, como os sindicatos, não tem se preocupado seriamente com o fenômeno da precarização e da flexibilização do trabalho, o que tem deixado os trabalhadores na defensiva. Tudo leva a crer que os sindicatos não vêm buscando organizar os trabalhadores contra essas 
práticas impostas pelas empresas capitalistas. Em Catalão, tanto o METABASE Sindicato dos Trabalhadores da Indústria e Extração do Ferro e Metais Básicos e de Minerais não Metálicos de Catalão-Ouvidor quanto o SIMECAT, filiados à central neoliberal Força Sindical, aderiram à política de concertação social. A tônica dessa política fica clara na análise que Mendes faz dos sindicatos e de seus dirigentes cada vez mais comprometidos com o patronato. De acordo com Mendes, os sindicatos enfrentam uma crise de identidade de grandes proporções. No interior dos movimentos sindicais, cresce a força de direita, que os levam ao imediatismo, à contingência, a operar sob o prisma constitucional e burocrático, atado ao ideário capitalista, criando um sindicalismo de participação, contrário de um sindicalismo de classe. Mendes (2007, p. 39) cita o depoimento do presidente do METABASE e de sua relação com os empresários, onde afirma que: "Nós fazemos os contatos com os empresários e existe uma relação de respeito mútuo, num clima de profissionalismo [...] essa relação se efetiva geralmente através de reuniões e através de ofícios de reivindicações buscando uma harmonia entre a classe trabalhadora e empresarial”. Aqui não resta dúvida quanto à relação de parceria e consenso que a direção desses sindicatos estabeleceram com o capital.

Outro aspecto relevante deste artigo, é que procuramos apreender as principais mudanças ocorridas no mundo do trabalho nas duas últimas décadas e, com elas, as implicações que tiveram nas condições materiais de existência, bem como no plano da consciência de classe dos trabalhadores. Em síntese, procuramos apreender as conseqüências dessas mudanças que tão profundamente tem afetado as condições objetivas e subjetivas da classe trabalhadora em Catalão, bem como em outras regiões do país.

\section{Referências}

ALVES, G. Trabalho e subjetividade. São Paulo: Boitempo, 2011.

A condição de proletariedade: A precariedade do trabalho no capitalismo

global. Londrina: Práxis, 2009.

O novo (e precário) mundo do trabalho: Reestruturação Produtiva e Crise do

Sindicalismo. São Paulo, Boitempo, 2000.

ANTUNES, R. O novo sindicalismo. São Paulo: Ed. Brasil Urgente, 1991. 
Dimensões da precarização estrutural do trabalho. In: DRUCK, G. e

FRANCO, T. (orgs.). A perda da razão social do trabalho: terceirização e precarização.

São Paulo: Boitempo, 2007.

. Adeus ao Trabalho? São Paulo: Cortez. UNICAMP, 2009.

Os sentidos do trabalho. São Paulo: Boitempo, 1999.

O que é sindicalismo. São Paulo: Círculo do Livro, 1992.

et al. Trabalho, Reestruturação Produtiva e Algumas Repercussões no

Sindicalismo Brasileiro. In: Neoliberalismo, Trabalho e Sindicatos - Reestruturação

Produtiva na Inglaterra e no Brasil, São Paulo: Boitempo, 1997a.

. et al. A terceira alternativa. In: Dilemas da Atualidade, São Paulo, Centro de Estudos Sindicais - CES, 1997b.

BOITO Jr. A; GALVÃO, A; MARCELINO, P. Brasil: o movimento sindical e popular na década de 2000. OSAL (Buenos Aires: CLACSO), Año X, Nº 26, octubre de 2009.

BOITO Jr., A. De volta para o novo corporativismo: a trajetória política do sindicalismo brasileiro. Em Perspectiva, n. 3, jul.-set./1994.

. Hegemonia Neoliberal e Sindicalismo no Brasil. Crítica Marxista, n.3, São

Paulo: Brasiliense, 1996.

. O sindicalismo de Estado no Brasil. São Paulo: Ed. Hucitec, 1991a.

Reforma e persistência da estrutura sindical. In: BOITO Jr. (Org.) O

sindicalismo nos anos 80. Rio de Janeiro: Paz e Terra, 1991b.

A Crise do sindicalismo. In: SANTANA, M. A. e RAMALHO, J. R, (Orgs.)

Além da fábrica - trabalhadores, sindicatos e a nova questão social, São Paulo,

Boitempo, 2003.

Ainda é possível renovar o sindicalismo. Entrevista especial com Armando Boito. IHU On-Line - Unisinos, 01/05/2008.

BOURDIEU, P. Contrafogos. Rio de Janeiro: Zahar, 1998.

A essência do neoliberalismo. Disponível em

http://infoalternativa.org/teoria/teo007.htm. Acesso em: 4 ago 2012.

CASTRO, N. A.; GUIMARÃES, A. S.. Trabalho, sindicalismo e reconversão industrial no Brasil nos anos 90. Lua Nova n. 22, 1990.

. Modernização e trabalho no complexo automotivo brasileiro: reestruturação industrial ou japanização de ocasião? Novos Estudos CEBRAP, n. 37, 1993. 
Trabalho e organização industrial num contexto de crise e reestruturação produtiva. São Paulo em Perspectiva, v. 8, n. 1, p. 116-132, São Paulo, 1994.

CATTANI, A. D. \& HOLSMANN, L. (Orgs.) Dicionário de Trabalho e Tecnologia. Porto Alegre: Ed.UFRS, 2006.

DE GRAZIA, G. Tempo de trabalho e desemprego. São Paulo: Xamã, 2007.

DRUCK, M. da Graça. Terceirização: (des)fordizando a fábrica. São Paulo: Boitempo Editorial, 1999.

Trabalho, precarização e resistências: novos e velhos desafíos?. Caderno CRH, Salvador, v. 24, p. 37-57, 2011.

. e FRANCO, T. A perda da razão social do trabalho: terceirização e precarização. São Paulo: Boitempo, 2007.

GITAHY, L. Inovação tecnológica, subcontratação e mercado de trabalho. São Paulo em Perspectiva, v. 8, n. 1, jan./mar., 1994.

GOUNET, T. Fordismo e toyotismo na sociedade do automóvel. São Paulo: Boitempo, 1999.

GRAMSCI, A. Cadernos do cárcere. Vol. 5. Rio de Janeiro: Civilização Brasileira, 2002, p. 11-128.

HARVEY, D. Condição pós-moderna. São Paulo: Edições Loyola, 1993.

IANNI, O. A sociedade global. Rio de Janeiro: Ed. Civilização Brasileira, 1992.

KULAIF, Y. A indústria de fertilizantes fosfatados no Brasil: perfil empresarial e distribuição regional. Rio de Janeiro: Ministério da Ciência e Tecnologia, Centro de Tecnologia Mineral, 1999.

MARQUES, Gislei Lemes; AVELAR, Gilmar Alves de. A precarização do trabalho metalúrgico na Mitsubishi Motors Company e as implicações na saúde do trabalhador. Estudos do Trabalho. ano 4, n. 7, 2010.

MARQUES, R. M. Globalização e Estados nacionais. Crítica Marxista, n. 3, São Paulo, Brasiliense, 1996.

MARX, K. e ENGELS, F. Manifesto comunista. São Paulo: Boitempo Editorial, 2010.

MARX, K. Grundrisse. São Paulo: Boitempo, 2011.

MENDES, L. O. Expansão do capital, territorialidade do trabalho e as respostas do SENAI em Catalão (GO) no século XXI: uma contribuição à geografia do trabalho. Dissertação de mestrado, defendida na UNESP de Presidente Prudente, 2007. 
MÉSZÁROS. István. Para além do Capital: rumo a uma teoria da transição, São Paulo: Boitempo Editorial, 2002.

OLIVEIRA, Eurenice de. Toyotismo no Brasil. São Paulo: Expressão Popular, 2004.

PADILHA, V. Qualidade de vida no trabalho num cenário de precarização: panacéia delirante. Trabalho, Educação e Saúde, Rio de Janeiro, v. 7, n. 3, p. 549-563, nov.2009/fev. 2010.

PEREIRA, Leonardo C. A reestruturação produtiva e o processo de trabalho em Catalão (Goiás): uma abordagem sobre o modo de vida da classe trabalhadora. Dissertação (Mestrado em sociologia) - Faculdade de Ciências Sociais (FCS), Universidade Federal de Goiás (UFG), 2012.

RAMALHO, J. R. Precarização do trabalho e impasses da organização coletiva no Brasil. In: Antunes, R. et al. (Orgs.), Neoliberalismo, Trabalho e Sindicatos: Reestruturação produtiva na Inglaterra e no Brasil. São Paulo: Boitempo Editorial, 1997.

RIBEIRO, R. e GUIMARÃES, E. N. A nova fronteira industrial do sudeste de Goiás. Disponível no sitio www.multiciencia.unicamp.br/artigos_06/rede_2.pdf. Acesso em dezembro de 2011.

ROSSO, S. Dal. Mais trabalho! São Paulo: Ed. Boitempo, 2008.

SANTOS, A. de O. A nova crise do sindicalismo internacional. In: ANTUNES, R. (Org.) Riqueza e miséria do trabalho no Brasil. São Paulo: Boitempo, 2006.

SANTANA, A. T. de. A territorialização da indústria automobilística em Catalão e as mudanças no trabalho. Dissertação (Mestrado em Geografia) - Universidade Federal de Goiás (UFG), Catalão, 2011.

SABEL, C. e PIORE, M. La segunda ruptura industrial. Madrid: Alianza Editorial, 1990.

DA SILVA, Magda Valéria. A indústria automobilística em Catalão/Goiás. Tese (Doutorado em Geografia) - Universidade Federal de Uberlândia, Uberlândia, 2010.

SILVA, Ronaldo da. A implantação da Mitsubishi em Catalão: estratégias políticas e territoriais da indústria automobilística nos anos 90. 2002. 143f. Dissertação (Mestrado em Geografia) - Instituto de Estudos Sócio-Ambientais, Universidade Federal de Goiás, Goiânia, 2002.

SOUSA, Erik R. B. Um estudo sobre o modelo de organização do trabalho na montadora Mitsubishi em Catalão. Monografia de conclusão de curso. Depto. de História e Ciências Sociais da Universidade Federal de Goiás, Catalão, 2010.

THOMPSON. E.P. Tempo, Disciplina de trabalho e capitalismo industrial. In Costumes em comum. São Paulo: Companhia das Letras, 1998. 
Tradición, revuelta y consciência de classe: Estudios sobre La crisis de la sociedad preindustrial. Barcelona: Editorial Crítica, 1987.

VASAPOLLO, Luciano. O trabalho atípico e a precariedade. São Paulo: Expressão Popular, 2005. 